\title{
Isolation of Chlamydia from women attending a clinic for sexually transmitted disease
}

\author{
D. C. MACD. BURNS, S. DAROUGAR, R. N. THIN, L. LOTHIAN, AND C. S. NICOL \\ From St. Bartholomew's Hospital, and the Institute of Ophthalmology, London
}

Non-specific genital infection (NSGI) in men is recognized by the presence of a urethral discharge which on investigation contains significant numbers of polymorphonuclear leucocytes but no identifiable pathogens. NSGI in men is also called non-gonococcal or non-specific urethritis (NSU). Recent studies have indicated that organisms of Chlamydia subgroup A may cause up to 45 per cent. of these infections in men (Lancet, 1974).

So far no corresponding clinical state can be easily identified in women. Furthermore, polymorphonuclear leucocytes are commonly present in the lower female genital tract and their number varies according to the stage of the menstrual cycle (Wachtel, 1969). In the absence of simple diagnostic criteria women are therefore usually diagnosed as having NSGI on epidemiological grounds (Oriel, Powis, Reeve, Miller, and Nicol, 1974). Recent reports have shown that women who are sexual contacts of men suffering from Chlamydia-positive NSU may harbour this organism (Dunlop, Hare, Darougar, Jones, and Rice, 1969; Dunlop, Hare, Darougar, and Jones, 1971; Dunlop, Vaughan-Jackson, Darougar, and Jones, 1972; Oriel, Reeve, Powis, Miller, and Nicol, 1972). In two other studies Chlamydia isolation rates of 31 per cent. (Hilton, Richmond, Milne, Hindley, and Clarke, 1974) and 18 per cent. (Oriel and others, 1974) have been reported among unselected women, including those with conditions other than NSGI, attending clinics for the treatment of sexually transmitted disease (STD). The object of this paper is to report the findings in a further series of 638 unselected women attending an STD clinic.

\section{Material and methods}

SELECTION OF CASES

All women attending the clinic with a fresh complaint between April 4, 1973, and February 20, 1974, were included in the survey. Women were placed in diagnostic groups according to the results of laboratory tests. In addition, the following definitions were used:

Received for publication March 14, 1975

Address for reprints: Dr. D. C. MacD. Burns,

c/o S.T.C., St. Bartholomew's Hospital, London
(1) Women who were known to have had sexual contact with a man suffering from NSGI are 'contacts of NSGI'.

(2) Women without apparent infection and with no known infected contact and in whom cultures for Chlamydia were negative are 'control women'.

\section{CLINICAL ASSESSMENT}

In taking the history, attention was given to details of genitourinary symptoms, sexual contacts, and contraceptive practice. The full lithotomy position was used for genital examination and a Cusco bivalve speculum was used to expose the cervix. The presence or absence of a cervical erosion was noted and specimens for microbiological examination were collected.

\section{LABORATORY TESTS}

Material from the vaginal fornices was stained by Gram's method and examined microscopically for yeast cells and hyphae of Candida species. A wet film of vaginal material was also examined microscopically for Trichomonas vaginalis. In addition vaginal material was inoculated (i) into Oxoid No. 2 Trichomonas Culture Medium and examined after 24 and $48 \mathrm{hrs}$ ' incubation, and (ii) on to Sabouraud's medium for culture for Candida species.

Specimens were collected from the urethral meatus and the cervical canal, stained by Gram's method, and examined for the presence of pus cells and Gram-negative intracellular diplococci. Urethral and cervical secretion was also collected on charcoal swabs and placed in Stuart's transport medium. Within $24 \mathrm{hrs}$ these were plated on to lysed blood agar containing vancomycin, colistin, trimethoprim, and natamycin ('Pimafucin') (Riddell and Buck, 1970). Neisseria gonorrhoeae was identified by sugar fermentation reactions using the serum-free medium described by Flynn and Waitkins (1972). When gonorrhoea was particularly suspected, specimens for Gram-staining and culture were also taken from the rectum via a proctoscope. Cervical material for cytological examination was collected with an Ayre's spatula, wet-fixed in alcohol and ether, and stained by Papanicolau's method. Smears were examined by an experienced cytologist who looked for malignant cells and evidence of inflammation (Simmons and Vosmik, 1974). These inflammatory changes were characterized by altered morphology, abnormal numbers of parabasal cells, and a significant increase in pus cells. The changes were graded on a scale $0, \pm,+,++,+++$. 
In addition to these routine investigations, material for Chlamydia culture was collected from the cervical canal with a plain cotton-wool swab which was placed in a plastic capsule containing 2SPS transport medium (2SP +3 per cent. foetal bovine serum and antibiotics) (Darougar, Jones, Kinnison, Vaughan-Jackson, and Dunlop, 1972). The capsule was then stored in a refrigerator at $-70^{\circ} \mathrm{C}$ for 3 to 6 weeks until the time of inoculation. Monolayers of irradiated McCoy cells were prepared in flat-bottomed tubes by the method used previously (Gordon, Harper, Quan, Treharne, Dwyer, and Garland, 1969). The clinical specimens were each inoculated into two tubes using the simplified one-passage technique of culture in irradiated McCoy cells (Darougar, Kinnison, and Jones, 1971). The inoculated cells, which were incubated at $35^{\circ} \mathrm{C}$ for approximately $60 \mathrm{hrs}$, were fixed and stained with Giemsa. The Giemsa-stained monolayers were examined for the presence of inclusions using a microscope with a $10 \times$ objective, $2 \times$ optovar, $8 \times$ oculars, and dark-field illumination.

\section{Results}

Chlamydia isolation rates (Table $\mathrm{I}$ )

Chlamydia cultures gave positive results in 76 (11.9 per cent.) of the 638 women studied. The findings were positive among forty ( 21.6 per cent.) of 185 women who were known to have had sexual contact with a man suffering from NSU ('contacts of NSGI'). Positive Chlamydia culture results were also obtained from fourteen (43.8 per cent.) of 32 women with gonorrhoea, eight (9.3 per cent.) of 86 with candidosis, three (13 per cent.) of 23 with trichomoniasis, and three ( 3.9 per cent.) of 77 with no STD and no known contact with an STD.

Under the heading 'other conditions' are grouped women with more than one infection or with other conditions such as genital warts, herpes, or urinary infections. Eight of these patients had positive results; seven were women with multiple infections and one was a woman who was a possible NSU contact.

In a further 41 cases the culture was overgrown with other organisms or the culture cells failed to grow satisfactorily.

\section{Incidence of genitourinary symptoms}

Genitourinary symptoms (such as vaginal discharge, dysuria, and vulval irritation) were significantly less common in Chlamydia-positive women than in
Chlamydia-negative women; 25 of 76 Chlamydiapositive women had genitourinary symptoms compared with 282 of 521 Chlamydia-negative women $\left(\chi_{2}{ }_{1}=10.04 ; P<0.05\right)$.

No particular symptoms or combination of symptoms appeared to predominate among the women harbouring Chlamydia. Symptoms in the Chlamydia-positive women were compared with symptoms in the 74 negative women without apparent infection and with no known infected contact ('control women'). Genitourinary symptoms were present in 43 of these control women, and were thus again less common among Chlamydia-positive women $\left(\chi^{2}{ }_{1}=7 \cdot 24 ; P<0.01\right)$.

\section{Oral contraception}

A total of 287 of the women took oral contraceptives; 37 (49 per cent.) of the Chlamydia-positive and 250 (50 per cent.) of the Chlamydia-negative women used oral contraception. Five women with gonorrhoea, 36 with candidosis, seven with trichomoniasis, and 82 contacts of NSGI took these preparations (Table II). Although the proportions vary between the different diagnostic groups, the differences are not significant.

TABLE II Use of oral contraceptives, by diagnosis

\begin{tabular}{|c|c|c|c|c|}
\hline Contraception & Gonorrhoea & Candidosis & Trichomoniasis & $\begin{array}{l}\text { NSGI } \\
\text { contacts }\end{array}$ \\
\hline $\begin{array}{l}\text { Oral } \\
\text { Other or none }\end{array}$ & $\begin{array}{r}5 \\
27\end{array}$ & $\begin{array}{l}36 \\
44\end{array}$ & $\begin{array}{r}7 \\
16\end{array}$ & $\begin{array}{l}82 \\
97\end{array}$ \\
\hline
\end{tabular}

$\left(\chi^{2} 3=1 \cdot 25 ; P>0 \cdot 7\right)$

Oral contraceptive use in Chlamydia-positive women varied between the different diseases but again these differences were not significant.

\section{Cervical erosion}

Among control women, those taking oral contraceptives had a significantly higher incidence of cervical erosion (Table III). Twelve J" fifteen patients with erosions were taking this form of contraception, while 38 of 59 women without erosions did not use oral contraception $\left(\chi^{2}{ }_{1}=7 \cdot 8 ; P<0.01\right)$. However, when the same comparison was made in women harbouring Chlamydia, no relationship was found (Table III) $\left(\chi^{2}{ }_{1}=0.06 ; P>0.05\right)$. In women not taking oral contraceptives, erosions were significantly commoner among those who were

TABLE I Incidence of Chlamydia in various sexually transmitted diseases

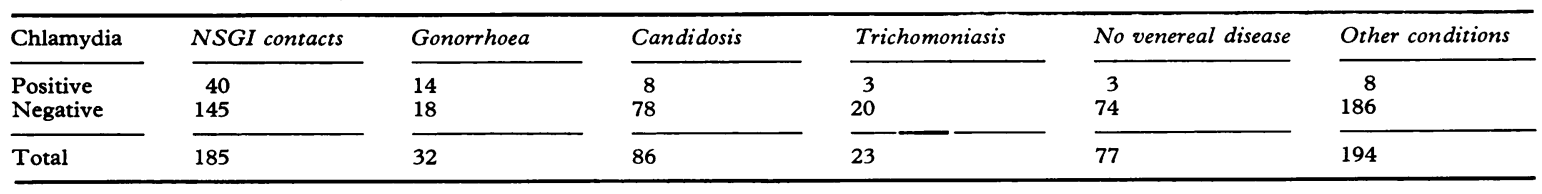


TABLE II I Oral contraception and cervical erosion

\begin{tabular}{|c|c|c|c|c|}
\hline \multirow{2}{*}{ Contraception } & \multicolumn{2}{|c|}{ Controls } & \multicolumn{2}{|c|}{ Chlamydia-positive } \\
\hline & Erosion & No erosion & Erosion & No erosion \\
\hline $\begin{array}{l}\text { Oral } \\
\text { Other or none }\end{array}$ & $\begin{array}{r}12 \\
3\end{array}$ & $\begin{array}{l}21 \\
38\end{array}$ & $\begin{array}{l}21 \\
16\end{array}$ & $\begin{array}{l}16 \\
21\end{array}$ \\
\hline
\end{tabular}

Chlamydia-positive. Sixteen of nineteen women with erosions and 21 of 59 women without erosions were Chlamydia-positive $\left(\chi^{2}{ }_{1}=11 \cdot 7 ; \mathrm{P}<0.001\right)$.

\section{Erosions in contacts of NSGI}

In contacts of NSGI with Chlamydia-positive culture results, there was no difference in contraceptive practice between the women who had cervical erosions and those who did not. Eleven of nineteen women with erosions used oral contraceptives and ten of nineteen women without erosions used them. These Chlamydia-positive contacts of NSGI were matched, by age, country of birth, and parity, against contacts of NSGI who were Chlamydia-negative; again there was no relation between contraception and cervical erosion in this group. Five of nine women with erosions and eighteen of 31 women without erosions took oral contraceptives (Table IV).

TABLE IV Oral contraception and erosions in NSGI contacts

\begin{tabular}{|c|c|c|c|}
\hline Chlamydia & Contraception & Erosion & No erosion \\
\hline Positive & $\begin{array}{l}\text { Oral } \\
\text { Other or none }\end{array}$ & $\begin{array}{r}11 \\
8\end{array}$ & $\begin{array}{r}10 \\
9\end{array}$ \\
\hline Negative & $\begin{array}{l}\text { Oral } \\
\text { Other or none }\end{array}$ & $\begin{array}{l}5 \\
4\end{array}$ & $\begin{array}{l}18 \\
13\end{array}$ \\
\hline
\end{tabular}

\section{Cytological inflammatory changes}

Contacts of NSGI who were Chlamydia-positive were matched by age, parity, country of birth, and oral contraceptive practice against contacts of NSGI who were Chlamydia-negative; the cytological features of inflammatory change in the cervical cells were equally common in both groups. Of the women with Chlamydia, 37 had inflammatory changes compared with 35 of the women without Chlamydia. On the other hand, only nineteen of a similarly matched group of 'control women' showed these changes. Table $\mathrm{V}$ shows that the difference between both the NSGI contact groups and the control group is significant $\left(\chi_{2}^{2}=26.5 ; P<0.001\right)$.

TABLE V Details of inflammatory changes

\begin{tabular}{|c|c|c|c|}
\hline \multirow[b]{2}{*}{ Inflammatory changes } & \multicolumn{2}{|c|}{ Contacts of NSGI } & \multirow[b]{2}{*}{ 'Control Women' } \\
\hline & $\begin{array}{l}\text { Chlamydia- } \\
\text { Positive }\end{array}$ & $\begin{array}{l}\text { Chlamydia- } \\
\text { Negative }\end{array}$ & \\
\hline $\begin{array}{l}\text { Present } \\
\text { Absent }\end{array}$ & $\begin{array}{r}37 \\
3\end{array}$ & $\begin{array}{r}35 \\
5\end{array}$ & $\begin{array}{l}19 \\
21\end{array}$ \\
\hline
\end{tabular}

Chlamydia in primary and secondary contacts

Contacts of NSGI were classified as often as possible into those who appeared to be primary contacts of a man with NSU and those who appeared to be secondary contacts. Of the Chlamydia-positive women 27 (67.5 per cent.) were primary contacts compared with only 44 (27.6 per cent.) of the Chlamydia-negative women (Table VI). This difference is unlikely to occur by chance.

TABLE VI Primary or secondary NSGI contacts

\begin{tabular}{lll}
\hline Contacts & $\begin{array}{l}\text { Chlamydia- } \\
\text { Positive }\end{array}$ & $\begin{array}{l}\text { Chlamydia- } \\
\text { Negative }\end{array}$ \\
\cline { 3 - 4 } Primary & 27 & 44 \\
Secondary & 5 & 65 \\
Unclassified & 8 & 36 \\
\hline
\end{tabular}

$\left(\chi^{2} 3=20 \cdot 2 ; P<0.001\right)$

\section{Discussion}

The overall Chlamydia isolation rate of 11.9 per cent. is lower than the rate of 31 per cent. recorded by Hilton, Richmond, Hindley, and Clarke (1974) or the rate of 18 per cent. reported by Oriel, Powis, Reeve, Miller, and Nicol (1974). The isolation rate from contacts of NSGI was 21.6 per cent. compared with 27 per cent. reported by Oriel and others (1974) and 34 per cent. reported by Hilton and others (1974). The Chlamydia findings in women with gonorrhoea, candidosis, and trichomoniasis lay between the rates reported by the other two groups. The isolation rate in women with gonorrhoea was higher than the rate in other conditions. It seems reasonable to suppose that isolation of Chlamydia may vary between laboratories since the incidence of genital sub-group A Chlamydia is likely to vary between women attending different clinics in different areas at different times.

Chlamydia was rarely found in women with no evidence of STD and no known contact with infection; although three (4 per cent.) of these women had Chlamydia it seems reasonable to regard the remaining 74 Chlamydia-negative women as satisfactory controls. Oriel and others (1974) defined a similar group and found only 2 per cent. of patients harbouring Chlamydia. Hilton and others (1974) studied women attending a family planning clinic and isolated Chlamydia from 3 per cent. of 63 patients. These findings support the concept that Chlamydia are pathogens in the genital tract and are sexually transmitted.

Symptoms were significantly less common among patients harbouring Chlamydia than among those without the agent. Symptoms were particularly common among women in whom no infection was found, many of whom presented because of their symptoms. In fact many women seeking reassurance 
present with symptoms which can be removed by examination and explanation only. Thus it is apparent that symptoms give no clue to the presence of Chlamydia in women.

Of the women in this series, 49 per cent. used oral contraception and their use was similar in Chlamydiapositive and Chlamydia-negative women. If women with gonorrhoea, trichomoniasis, candidosis, and women contacts of NSGI are considered alone, 41 per cent. of 314 women took oral contraceptives compared with 49 per cent. of the 65 Chlamydia-positive women with these conditions, but the difference between these proportions is not significant. The findings reported here are similar to those of Oriel and others (1974), but Hilton and others (1974) found a significantly higher incidence of oral contraceptive use among Chlamydia-positive women. They suggested that oral contraceptives might activate latent Chlamydia, but the findings here suggest that the presence of Chlamydia appears to be unrelated to the presence of another infection or to the use of oral contraception.

Among control women, the presence of cervical erosion was related to the use of oral contraceptives. However, this relationship was not observed among women harbouring Chlamydia. When women not taking oral contraceptives were examined separately, erosion was commoner in Chlamydia-positive than in Chlamydia-negative women. Oriel and others (1974) used slightly different criteria for cervical abnormality but made similar observations. In the present series of women in contact with NSGI, whether Chlamydia-positive or negative, no relationship was observed between the presence of cervical erosion and the use of oral contraceptives. The present findings suggest that the simultaneous presence of oral contraceptive hormones and Chlamydia modify the factors affecting the position of the squamocolumnar junction. Also the naked eye appearance of the cervix may be modified by the presence of follicles which have been observed at colposcopic examination (Dunlop, Hare, Darougar, and Dwyer, 1973).

An interesting feature in this series was the presence of the cytological features of inflammatory change in the cervical cells of contacts of NSGI. These changes were more common in contacts who were Chlamydia-positive and Chlamydia-negative than in control women. Simmons and Vosmik (1974) also reported that changes were more common in contacts of NSGI than in a similar group of control women. No difference was found between women contacts who were Chlamydia-positive and who were Chlamydia-negative, so that cervical cytology does not appear to offer a simple means of detecting the presence of Chlamydia. However, cervical smears are taken from many women and their preparation and examination is now relatively easy. We believe that they should be taken routinely in STD clinics, and that the inflammatory changes merit further study.

The higher rate of Chlamydia isolation in women contacts of NSGI who were primary contacts compared with secondary contacts is similar to observations made by Oriel and others (1974). They also noted that women who were sexual contacts of men with first attacks of NSU were more likely to have Chlamydia than those who were contacts of men with recurrent NSU. A similar tendency was found in the present series of patients and we believe this merits further study.

A great many problems remain concerning NSGI. We agree with others that Chlamydia is a genital pathogen (Lancet, 1974) and that a significant number of infections exist among women attending an STD department. As Chlamydia do not produce distinctive clinical features, culture is essential and where laboratory facilities exist this investigation should be included in the routine screening of women when they first attend an STD clinic.

\section{Summary}

Cervical swabs for Chlamydia culture were collected from 638 unselected women attending a sexually transmitted diseases clinic with a fresh complaint. Chlamydia were isolated from 76 (12 per cent.) of the women. When the results were related to the patients' diagnoses, Chlamydia were present in 44 per cent. of women with gonorrhoea and in 22 per cent. of women who were contacts of men with nonspecific urethritis (women who may be regarded as having non-specific genital infection). Chlamydia were uncommon in women with no evidence of genital infection.

Significant correlations were found between the presence of Chlamydia and cervical erosion, cervical cytological inflammatory change, and absence of symptoms. Isolates were obtained more frequently from women with non-specific genital infection who were primary contacts than from women who were secondary contacts.

These findings support the concept that Chlamydia are pathogens in the genital tract and are sexually transmitted.

Our thanks are due to Dr. G. Canti and Dr. O. M. Curling for their invaluable cytological assessment and help. We also acknowledge the contribution of the late Dr. H. H. Tanner at the beginning of this study and the encouragement and support of Professor B. R. Jones throughout the work.

\section{References}

Darougar, S., Jones, B. R., Kinnison, J. R., VaughanJACKSON, J. D., and DunLoP, E. M. C. (1972) Brit. F. vener. Dis., 48, 416 
KInNISON, J. R., and Jones, B. R. (1971) In 'Trachoma and Related Disorders', ed. R. L. Nichols, p. 63. Excerpta Medica, Amsterdam

Dunlop, E. M. C., Hare, M. J., Darougar, S., and DWYer, R. St. C. (1973) Brit. F. vener. Dis., 49, 301 , - — , and Jones, B. R. (1971) In 'Trachoma and Related Disorders' ed. R. L. Nichols, p. 494. Excerpta Medica, Amsterdam

Dis., 120, 463

-, Vaughan-Jackson, J. D., Darougar, S., and JONES, B. R. (1972) Brit. F. vener. Dis., 48, 425

FlyNN, J., and WAITKINS, S. A. (1972) $\mathcal{F}$. clin. Path., 25, 525

Gordon, F. B., Harper, I. A., QuAN, A. L., Treharne, J. D., DWYER, R. St. C., and GARLAND, J. A. (1969) f. infect. Dis., 120, 451
Hilton, A. L., Richmond, S. J., Milne, J. D., Hindley, F., and Clarke, S. K. R. (1974) Brit. F. vener. Dis., 50,1

Lancet (1974) 2, 264

Oriel, J. D., Powis, P. A., Reeve, P., Miller, A., and Nicol, C. S. (1974). Brit. F. vener. Dis., 50, 11

Riddell, R. H., and Buck, A. C. (1970) f. clin. Path., 23, 481

Simmons, P. D., and Vosmik, F. (1974) Brit. F. vener. Dis., 50, 313

WaChtel, E. G. (1969) 'Exfoliative Cytology in Gynaecological Practice', 2nd ed., p. 41. Butterworths, London 